\title{
On philosophy of mind, quantum physics and metaphysics \\ of the uni-multiverse
}

\author{
Paolo Di Sia ${ }^{1-3}$ \\ ${ }^{1}$ School of Science \& School of Medicine (Department of Neuroscience), University of Padova, \\ Via Jappelli 1, 35121 Padova, Italy \\ ${ }^{2}$ Faculty of Science and Technology, Free University of Bozen-Bolzano, Piazza Università 5, \\ 39100 Bozen-Bolzano, Italy \\ ${ }^{3}$ Corresponding author e-mail address: paolo.disia@gmail.com
}

\begin{abstract}
Metaphysics, as discipline dealing with the most fundamental aspects of reality, studies the essence of entities, leaving to particular sciences the study of empirical, specific, changeable and unstable aspects. In this sense metaphysics is close to ontology, tackling problems as the existence of God, the being in himself, the immortality of consciousness, the origin and meaning of the universe. Speculative physics pushes its interest to metaphysical questions too, both at a technical (mathematical) level, and at the level of thought (in relation to philosophy). In recent years interesting concepts and ideas have been considered and developed, involving the latest unified quantum-relativistic theories and the consequences on reality deriving from them.

The search for a meaning of life, one of Anscombe's themes, finds ferment in the search for meaning about the existence of our universe in itself and as a possible part of a multiverse containing it.

The problem of measurement in quantum mechanics appears from the application of the mathematical formalism to macroscopic situations and the central position of the observer in this process has produced a deviation towards a metaphysical subjectivism. There are controversial aspects about the role of consciousness in the process of reducing the wave function of quantum mechanics. This narrows the field of validity of some fundamental principles during the interaction between microsystems and macrosystems, with consequent diversification of the
\end{abstract}


definition of the ontological state of consciousness and reality. (Local) holism has often been linked to Wittgenstein. From Wittgenstein's answers to the paradoxes of communication and conceptual relativism, a tension emerges in his vision of linguistic games and in his mental experiments, traditionally interpreted in contrasting ways. This tension can be better understood through some reflections by Wittgenstein on Einstein and his theory of relativity.

Keywords: Philosophy of mind, Contemporary physics, Wave function, Metaphysics, Consciousness, Ontology, Holism, Uni-Multiverse, Meaning.

\section{References}

[1] P. Di Sia, Approaching youngs to unified theories: the charm of string theories, Procedia Social and Behavioral Sciences Journal (Elsevier), 174C, 10-16 (2015).

[2] P. Di Sia, Fine-Tuning, Universo, Multiverso - tra Scienza, Filosofia e Teismo, Roma: Aracne Editrice (in press) (2019).

[3] R. T. Cahill, C. M. Klinger, Pregeometric modeling of the spacetime phenomenology, Physics Letters A, 223 (5), 313-319 (1996).

[4] P. Di Sia, About the existence of the universe among speculative physics, metaphysics and theism: an interesting overview, International Letters of Social and Humanistic Sciences (ILSHS), 9(1), 36-43 (2015).

[5] P. Di Sia, Exciting Peculiarities of the Extreme Physics, Journal of Physics: Conference Series, 442 (1), 012068 (6 pp.) (2013).

[6] P. Di Sia, Spacetime unified current models and deterministic computation, Journal of Science, 5(2), 65-67 (2015).

[7] P. Di Sia, Spazi di Calabi-Yau e teorie di stringa, Periodico di Matematiche, VIII, 6(3), 49-59 (2006).

[8] S.-T. Yau, S. Nadis, The Shape of Inner Space: String Theory and the Geometry of the Universe's Hidden Dimensions, New York: Basic Books (Reprint ed.) (2012).

[9] P. Di Sia, About the peculiar Aspects of Relativity and beyond: a pedagogical Perspective, American Journal of Educational Research, 2(6), 357-360 (2014), doi: 10.12691/education-2-6-4. 
[10] N. Bostrom, Are You Living In a Computer Simulation?, Philosophical Quarterly, 53(211), 243-255 (2003).

[11] L. Susskind, J. Lindesay, An Introduction To Black Holes, Information And The String Theory Revolution - The Holographic Universe, Singapore: World Scientific Pub Co Inc (2004). [12] R. Lanza, B. Berman, Biocentrism: How Life and Consciousness Are the Keys to Understanding the True Nature of the Universe, Dallas: Benbella Books (2010).

[13] P. Di Sia, Looking at the Dimension of Time among Science, Psychology and Everyday Reality, International Letters of Social and Humanistic Sciences (ILSHS), 1(2), 146-153 (2015).

[14] L. M. Surhone, M. T. Timpledon, S. F. Marseken (Eds), Chaotic Inflation Theory: Inflation (Cosmology), Big Bang, Chaos Theory, Observable Universe, False Vacuum, Steady State Theory, Mauritius: Betascript Publishing (2010).

[15] D. Wallace, The Emergent Multiverse: Quantum Theory according to the Everett Interpretation, Oxford: Oxford University Press (Reprint ed.) (2014).

[16] K. J. Kraay, The Theistic Multiverse: Problems and Prospects, in: Y. Nagasawa (Ed.), Scientific Approaches to the Philosophy of Religion, Houndsmills: Palgrave MacMillan (2012).

[17] P. Di Sia, On Quantum Physics, Metaphysics and Theism, in: Relations. Ontology and Philosophy of Religion, Sesto San Giovanni: Mimesis International (2018).

[18] N. Bohr, Can quantum-mechanical description of physical reality be considered complete?, The Physical Review, 48, 696-702 (1935).

[19] J. von Neumann, Mathematical Foundations of Quantum Mechanics, Princeton: Princeton University Press (Reprint ed.) (1996).

[20] E. P. Wigner, Remarks on the mind-body question, in: John Heil (Ed.), Philosophy of Mind: A Guide and Anthology, Oxford: Oxford University Press (2003).

[21] D. Albert, B. Loewer, Interpreting the many worlds interpretation, Synthese, 86, 87-98 (1988).

[22] D. Bohm, A suggested interpretation of the quantum theory in terms of Hidden Variables I and II, The Physical Review, 48, 166-179, 180-193 (1952).

[23] H. Everett, Relative state formulation of quantum mechanics, Review of modern physics, 29, 454-462 (1957). 
[24] G. C. Ghirardi, A. Rimini, T. Weber, Unified dynamics for microscopic and macroscopic systems, The Physical Review D, A42, 470-491 (1986).

[25] M. Gell-Mann, J. B. Hartle, Quantum mechanics in the light of cosmology, in: 3rd International symposium on the foundations of quantum mechanics in the light of new technology, Tokyo, Physical Society of Japan (1989).

[26] W. H. Zurek, Decoherence and the transition from quantum to classical, Physics Today, 3644 (1991).

[27] C. Penco, Matematica e gioco linguistico, Wittgenstein e la filosofia della matematica del '900, Firenze: Le Monnier (1981).

[28] C. Penco, Wittgenstein, Locality and Rules, Wittgenstein Today, 249-74 (2004).

[29] G. E. M. Anscombe, Introduzione al 'Tractatus' di Wittgenstein, Roma: Ubaldini (1966).

[30] R. J. Fogelin, Wittgenstein, London-New York: Routledge \& Kegan Paul (1976).

[31] E. Grimi, G. E. M. Anscombe. The Dragon Lady (con testimonianze inedite), Siena: Cantagalli (2014).

[32] R. Monk, Ludwig Wittgenstein: The Duty of Genius, New York: Penguin Books $(1990 / 1991)$.

[33] Available online (August 14, 2019): http://gf2045.com/.

[34] R. Kurzweil, The Singularity is Near: When Humans Transcend Biology, New York: Viking Press (2005).

[35] P. Di Sia, Relativistic nano-transport and artificial neural networks: details by a new analytical model, International Journal of Artificial Intelligence and Mechatronics (IJAIM), 3(3), 96-100 (2014).

[36] M. A. Lebedev, M. A. L. Nicolelis, Brain-machine interfaces: past, present and future, TRENDS in Neurosciences, 29(9), 536-546 (2006).

[37] J. Blascovich, J. Bailenson, Infinite Reality, New York: HarperCollins Publishers (2011).

[38] P. Di Sia, Looking at the Quantum Internet, International Academic Journal E-methodology, 4, 31-35 (2017), doi: 10.15503/emet2017.31.35.

[39] N. Kumar Bhadra, P. Di Sia, MIND AND CONSCIOUSNESS AS CREATED BY ELECTROMAGNETIC FORCE, International Journal of Applied and Advanced Scientific Research (IJAASR), 4(1), 1-6 (2019), doi: http://doi.org/10.5281/zenodo.2573101. 
[40] J. S. Bell, Speakable and unspeakable in Quantum Mechanics, Cambridge: Cambridge University Press (1987).

[41] L. Nichol (Ed.), The Essential David Bohm, London: Routledge (2002).

[42] P. Di Sia, FISICA MODERNA, COSCIENZA, MULTIVERSO, AZIONE DIVINA Problemi, dubbi, convergenze, Roma: Stamen (2018). 